\title{
Epidemiology of paediatric chronic fatigue syndrome in Australia
}

\author{
Sarah Knight, ${ }^{\oplus}$ 1,2,3 Shane Elders, ${ }^{1}$ Jill Rodda, ${ }^{1}$ Adrienne Harvey, ${ }^{1}$ Lionel Lubitz, ${ }^{4}$ \\ Kathy Rowe, ${ }^{5}$ Colette Reveley, ${ }^{4}$ Sabine Hennel, ${ }^{6}$ Susan Towns, ${ }^{7}$ Kasia Kozlowska, ${ }^{7}$ \\ Donald N Payne, ${ }^{8,9}$ Sonya Marshall-Gradisnik, ${ }^{10}$ Adam Scheinberg ${ }^{1,2,3}$
}

\begin{abstract}
- Additional material is published online only. To view, please visit the journal online (http://dx.doi.org/10.1136/ archdischild-2018-316450)

For numbered affiliations see end of article.
\end{abstract}

Correspondence to Dr Sarah Knight, Neurodisability and Rehabilitation, Murdoch Children's Research Institute Melbourne 3052, Australia; sarah.knight@mcri.edu.au

Received 24 October 2018 Revised 16 December 2018 Accepted 1 February 2019

\section{Check for updates}

(C) Author(s) (or their employer(s)) 2019. No commercial re-use. See rights and permissions. Published by BMJ.

To cite: Knight $S$, Elders $S$, Rodda J, et al. Arch Dis Child Epub ahead of print: [please include Day Month Year]. doi:10.1136/

archdischild-2018-316450

\begin{abstract}
Objective To estimate the paediatrician-diagnosed incidence of chronic fatigue syndrome (CFS) in Australia, and describe demographic and clinical features, as well as approaches to diagnosis and management.

Methods The Australian Paediatric Surveillance Unit facilitates monthly national surveillance of uncommon conditions seen by paediatricians. Data from young people aged $<18$ years diagnosed with CFS were collected. Incidence was estimated based on new cases reported from April 2015 to April 2016.
\end{abstract}

Results A total of 164 cases of newly diagnosed CFS in young people aged 4-17 years were identified for inclusion. The estimated national incidence for children aged $4-9$ years was 0.25 per 100000 per annum. In children aged 10-17 years, the estimated incidence of paediatrician-diagnosed cases for Victoria (17.48 per 100000 ) was substantially greater than other Australian states (range 1.31-5.51 per 100000 ). Most cases were female and Caucasian, most commonly presenting after an infectious illness with symptoms gradual in onset. The majority were diagnosed at least 13 months after symptom onset. Symptoms, associations, investigations and management strategies were highly variable.

Conclusions Current findings suggest that, consistent with other countries, the Australian incidence of CFS in children aged $<10$ years is very low. In contrast, the national incidence of CFS in older children and adolescents (aged 10-17 years) is more unclear, with marked variability between geographical regions apparent. This may be due to variation in service accessibility and clinician understanding of CFS. Accordingly, national initiatives to improve equity of care for children with CFS may be required.

Chronic fatigue syndrome (CFS) is a condition of unknown aetiology characterised by severe, persistent, unexplained fatigue. This fatigue may be accompanied by other symptoms including postexertional malaise, pain, cognitive deficits and disrupted sleep. ${ }^{1}$ In children and adolescents, CFS can lead to significant functional impairment, including a substantial reduction in school attendance. $^{2}$

As the aetiology of CFS is unknown and there is no diagnostic test for CFS, ${ }^{3}$ it is diagnosed clinically through the use of case definitions. ${ }^{4}$ Several case definitions and terminologies for CFS have been used internationally in clinical practice and research since the first case definition was published in 1988.5

\section{What is already known on this topic?}

Paediatric chronic fatigue syndrome (CFS) causes significant disability.

- Estimates of the incidence of paediatric CFS vary.

- We know little about how common the condition is or how it is currently managed in Australia.

\section{What this study adds?}

- CFS is uncommon in children aged $<10$ years.

- The Australian incidence of CFS in older children and adolescents (aged 10-17 years) is unclear, with marked variability between geographical regions apparent.

Epidemiological estimates of prevalence for CFS vary significantly. A meta-analysis of adult studies found estimates of prevalence varying between $0.2 \%$ and $6.41 \%$, with a pooled prevalence of $3.48 \%$ for self-reported cases, and $0.76 \%$ for clinically assessed cases. ${ }^{6}$ There is less literature specifically examining the epidemiology of paediatric CFS, with varying prevalence estimates ranging from $0 \%$ to $2.91 \% .^{7-18}$ Four published studies, from the Netherlands, Norway and the UK, report variable incidence rates of paediatric CFS with estimates ranging from $12(0.012 \%)$ to $500(0.5 \%)$ per $100000 .^{781920}$ Some of the variation in incidence estimates may be explained by variation in diagnostic methods, case ascertainment and age range captured.

The primary aim of this study was to provide an estimate of the paediatrician-diagnosed incidence of CFS in Australian young people, based on prospective national reporting by paediatricians. Secondary aims were to describe demographics, symptomatology, diagnosis and management of CFS, based on reported cases.

\section{PATIENTS AND METHODS}

The Australian Paediatric Surveillance Unit (APSU) facilitated national surveillance of CFS in young people aged under 18 years from April 2015 to April 2016. The APSU undertakes national surveillance of rare paediatric conditions in Australia. ${ }^{21}$ Each month clinicians on the APSU contact database are 
emailed a report card listing conditions currently being studied by the APSU. Clinicians are asked to report children newly diagnosed. In April 2015-April 2016, the total number of paediatricians reporting to the APSU was 1467 and the overall monthly report card return rate was 93\%. According to the Australia Government Department of Health, there were 2059 paediatricians employed in Australia in $2015^{22}$; therefore, approximately $71 \%$ of Australian paediatricians reported to the APSU at the time of the study.

Paediatricians received a protocol which included CFS case definition (online supplement 1). Reportable cases were defined as young people aged under 18 years, who were newly diagnosed with CFS in the past month. The upper age limit was defined by the APSU. CFS was defined according to the Centers for Disease Control and Prevention Case Definition (modified for a paediatric population under the auspices of the Royal Australasian College of Physicians). ${ }^{23}$ For every newly reported case, paediatricians completed a 20-item questionnaire which included: date of birth, sex, postcode, ethnicity, presenting symptoms including duration, type of onset, severity of and triggers for symptoms, comorbid conditions, family history, investigations undertaken and advised management.

\section{DATA ANALYSIS}

Data were analysed using Stata V.14.1 (StataCorp, 2016). Population data from the Australian Bureau of Statistics were used to calculate estimates of incidence of CFS. Values were calculated as the mathematical average of the 2015 and 2016 population estimates to coincide with the current study data collection period. Poisson regression was used to determine estimated incidences and were presented as rates per 100000 persons per annum, with 95\% CIs. National level incidence estimates for all children aged 4-9 years, all adolescents aged 10-17 years, female adolescents aged 10-17 years and male adolescents aged 10-17 years, were calculated. Age ranges were determined based on previous epidemiological studies in the paediatric CFS literature to allow for comparison of results. State-specific and gender-specific incidences were not calculated for the 4-9 years due to the low number of reports. In two cases, paediatricians failed to report the sex of the young person. In order to prevent under-reporting of male and female incidences, the female incidence assumed these two individuals were female, while the male incidence assumed they were male.

The characteristics of CFS were presented as frequencies and percentages of the total sample of reported cases. Missing data from the questionnaire were categorised in the results as being 'not specified'. Chi-square analyses were used to compare demographics and clinical characteristics of Victorian patients with those in other states and territories. Due to multiple comparison, $\mathrm{p}<0.01$ was considered to be statistically significant.

\section{RESULTS}

\section{Incidence estimates}

Between April 2015 and April 2016, 191 cases were reported to the APSU. Questionnaires were returned for 184 (96\%) cases, and 164 were confirmed as CFS cases. Of the remaining cases for which questionnaires were returned, 10 were duplicates and 10 were classified as errors (administrative errors or cases outside the case definition or age range). Ages ranged from 4 to 17 years for the 164 young people with confirmed CFS. Five confirmed cases were children aged 4-9 years, while 159 were adolescents aged $10-17$ years.

The estimated national incidence of paediatrician-diagnosed cases of CFS was 0.25 per 100000 per annum (95\% CI 0.08 to 0.59 ) for children aged 4-9 years, and 6.38 per 100000 per annum (95\% CI 5.43 to 7.45 ) for adolescents aged 10-17 years. Estimated national incidence for adolescent males was 3.68 per 100000 per annum (95\% CI 2.70 to 4.89), and 9.39 per 100000 per annum (95\% CI 7.75 to 11.28$)$ for adolescent females. There was mild variation in the estimated incidence rates of paediatrician-diagnosed cases of CFS for adolescents according to state or territory of Australia, but incidence rate of CFS in adolescents for the state of Victoria (17.48 per 100 000) was greater when compared with other Australia states (range 1.31-5.51 per 100 000) (table 1). During the study period, the rates of reporting of CFS were disproportionally higher in some states and unexpectedly low in others compared with non-CFS conditions being reported to the APSU (online supplement 2).

\section{Demographics}

Average age of included cases was 14.9 years (95\% CI 14.6 to 15.2) (table 2). Females constituted $68.9 \%$ of cases (female-tomale ratio $=2.3: 1)$. Majority of cases $(95.1 \%)$ were Caucasian. Patient demographics did not differ between regions; therefore, national data are reported.

\section{Morbidity}

There were no differences in symptomatology between Victorian patients and those in other states; therefore, national data reported (table 3). The most common pattern for onset of symptoms was gradual (56\% cases), while $37 \%$ were sudden. Fifty-two per cent of diagnoses were made at least 13 months after symptom onset, while $29 \%$ were diagnosed after 24

\begin{tabular}{|c|c|c|c|}
\hline & Total & Female & Male \\
\hline New South Wales & 3.16 (2.04 to 4.66$)$ & 4.16 (2.38 to 6.75$)$ & 2.45 (1.18 to 4.51$)$ \\
\hline Western Australia & 5.51 (3.08 to 9.08$)$ & 9.74 (5.18 to 16.65$)$ & $1.44(0.17$ to 5.20$)$ \\
\hline Queensland & 1.31 (0.53 to 2.71$)$ & $1.54(0.42$ to 3.95$)$ & 1.10 (0.23 to 3.21$)$ \\
\hline Tasmania & 3.61 (0.44 to 13.04$)$ & 7.48 (0.91 to 27.02$)$ & 0 \\
\hline Australian Capital Territory & $5.22(0.63$ to 18.85$)$ & 10.65 (1.29 to 38.47$)$ & 0 \\
\hline South Australia & $1.17(0.14$ to 4.22$)$ & 0 & 2.28 (0.28 to 8.24$)$ \\
\hline National & 6.38 (5.43 to 7.45$)$ & 9.39 (7.75 to 11.28$)$ & 3.68 (2.70 to 4.89$)$ \\
\hline
\end{tabular}

Rates are per 100000 and are age-adjusted to the 2015-2016 Australian Bureau of Statistics Census data.

CFS, chronic fatigue syndrome. 


\begin{tabular}{lc}
\hline \multicolumn{1}{l}{ Table 2 Demographics for included cases } \\
\hline \multicolumn{2}{l}{$n(\%)$} \\
\hline Age, mean $(95 \% \mathrm{Cl})$ & $14.9(14.6$ to 15.2) \\
\hline Gender & \\
\hline Female & $113(69)$ \\
\hline Male & $49(30)$ \\
\hline Not specified & $2(1)$ \\
\hline State & $108(66)$ \\
\hline Victoria & $25(15)$ \\
\hline New South Wales & $17(10)$ \\
\hline Western Australia & $7(4)$ \\
\hline Queensland & $2(1)$ \\
\hline South Australia & $2(1)$ \\
\hline Tasmania & $2(1)$ \\
\hline Australian Capital Territory & $1(1)$ \\
\hline Northern Territory & $156(95)$ \\
\hline Ethnicity & $1(1)$ \\
\hline Caucasian & $1(1)$ \\
\hline African/Middle Eastern & $6(4)$ \\
\hline Indigenous & \\
\hline Unknown/not specified &
\end{tabular}

months. For approximately two-thirds of patients, an infectious illness was reported as the trigger for symptom onset. On average, individuals had 9.9 symptoms $(95 \% \mathrm{CI} 9.2$ to 10.4$)$ over the course of their illness. The seven most common symptoms, being fatigue, postexertional malaise, sleep disturbance/ unrefreshing sleep, headache, attention/concentration difficulties, light-headedness/dizziness and musculoskeletal pain, were present in more than two-thirds of patients. Symptom severity was reported as moderate for $63.4 \%$ of cases.

The most commonly associated medical condition was postural orthostatic tachycardia syndrome (POTS), observed in $26.2 \%$ of patients (table 4). Joint hypermobility, fibromyalgia/ chronic widespread pain and migraines were present in over $10 \%$ of cases. No medical comorbidities were reported for $41 \%$ of patients and most patients (59.8\%) did not have any reported comorbid psychiatric conditions. Paediatricians reported that anxiety and depression ( $26 \%$ and $13 \%$ of cases, respectively) were the most common psychiatric comorbidities. In terms of self-reported family history, patients were reported to have a first-degree relative with anxiety disorder (18\%), depression $(17 \%)$ or CFS (13\%), respectively. There was no relevant family history for $50 \%$ of patients.

\section{Investigations}

Clinicians requested a variety of investigations (online supplement 3). As there were no major observed differences in requested investigations according to state, total results are presented. Eight tests were ordered for $>50 \%$ of cases: full blood count and differential urea, electrolytes and creatinine, thyroid function tests, erythrocyte sedimentation rate, liver function tests, Epstein-Barr virus (EBV) serology, C reactive protein and coeliac screen. The investigations that had the highest proportion of abnormal results were EBV serology (34\%), allergy tests (33\%), cytomegalovirus serology (25\%), serum vitamin D (24\%) and antinuclear antibodies (ANA) (23\%).
Table 3 Medical characteristics of included cases

\begin{tabular}{|c|c|}
\hline & $n(\%)$ \\
\hline \multicolumn{2}{|l|}{ Symptom onset } \\
\hline Gradual & $92(56)$ \\
\hline Sudden & $60(37)$ \\
\hline Unknown/not specified & $12(7)$ \\
\hline \multicolumn{2}{|l|}{ Symptom duration prior to diagnosis } \\
\hline 3-6 months & $10(18)$ \\
\hline $7-12$ months & $45(27)$ \\
\hline 13-24 months & $38(23)$ \\
\hline$>24$ months & $47(29)$ \\
\hline Not specified & $3(2)$ \\
\hline \multicolumn{2}{|l|}{ Trigger for onset } \\
\hline Infectious illness & $109(67)$ \\
\hline Psychological stress & $129(7)$ \\
\hline Non-infectious illness & $11(7)$ \\
\hline Injury & $4(2)$ \\
\hline Human papillomavirus vaccination & $3(2)$ \\
\hline Menarche & $2(1)$ \\
\hline Physical exertion & $2(1)$ \\
\hline Unknown/not specified & $42(26)$ \\
\hline \multicolumn{2}{|l|}{ Presenting symptoms } \\
\hline Fatigue & $163(99)$ \\
\hline Postexertional malaise & $138(84)$ \\
\hline Sleep disturbance/unrefreshing sleep & $134(82)$ \\
\hline Headache & $126(77)$ \\
\hline Attention/concentration difficulties & $122(74)$ \\
\hline Light-headedness/dizziness & $118(72)$ \\
\hline Musculoskeletal pain & $110(67)$ \\
\hline Difficulty processing information & $89(54)$ \\
\hline Gastrointestinal symptoms & $87(53)$ \\
\hline Flu-like symptoms & $79(48)$ \\
\hline Cardiovascular symptoms & $62(38)$ \\
\hline Abdominal pain & $48(29)$ \\
\hline Loss of thermostatic ability & $46(28)$ \\
\hline Joint pain & $45(27)$ \\
\hline Susceptibility to viral infections & $43(26)$ \\
\hline Hypersensitivity to noise or light & $42(26)$ \\
\hline Short-term memory loss & $29(18)$ \\
\hline Marked weight change & $23(14)$ \\
\hline Chest pain & $22(13)$ \\
\hline Motor symptoms & $19(12)$ \\
\hline New sensitivities to food or medications & $16(10)$ \\
\hline Perceptual/sensory disturbance & $15(9)$ \\
\hline Respiratory symptoms & $14(9)$ \\
\hline Genitourinary symptoms & $9(6)$ \\
\hline Pain (unspecified) & $6(4)$ \\
\hline Syncope & $2(1)$ \\
\hline Other & $7(4)$ \\
\hline Symptoms not specified & $1(1)$ \\
\hline Number of symptoms, mean $(95 \% \mathrm{Cl})$ & 9.9 (9.2 to 10.4$)$ \\
\hline \multicolumn{2}{|l|}{ Symptom severity } \\
\hline Mild & $18(11)$ \\
\hline Moderate & $104(63)$ \\
\hline Severe & $37(23)$ \\
\hline Very severe & $1(1)$ \\
\hline Not specified & $4(2)$ \\
\hline
\end{tabular}

\section{Management}

Most commonly used services were teacher and schoolbased services (42\%) and specialised CFS services (40\%) (online supplemen 4). Psychology (27\%) and physiotherapy services $(20 \%)$ were generally included. Paediatricians reported 


\begin{tabular}{|c|c|}
\hline & $n(\%)$ \\
\hline \multicolumn{2}{|l|}{ Comorbid medical conditions } \\
\hline Postural orthostatic tachycardia syndrome & $43(26.2)$ \\
\hline Joint hypermobility & $21(12.8)$ \\
\hline Fibromyalgia/chronic widespread pain & $17(10.4)$ \\
\hline Migraine & $17(10.4)$ \\
\hline Inflammatory bowel disease/functional bowel disorder & $14(8.5)$ \\
\hline Dysmenorrhoea & $12(7.3)$ \\
\hline Multiple food or chemical sensitivities/food intolerance & $9(5.5)$ \\
\hline Diabetes and other endocrine disorders & $4(2.4)$ \\
\hline Inflammatory bowel disease/coeliac disease & $3(1.8)$ \\
\hline Atopic syndrome & $2(1.2)$ \\
\hline Other & $8(4.9)$ \\
\hline No medical conditions specified & $67(40.9)$ \\
\hline \multicolumn{2}{|l|}{ Comorbid psychiatric conditions } \\
\hline Anxiety & $43(26.2)$ \\
\hline Depression & $22(13.4)$ \\
\hline Somatisation & $5(3.0)$ \\
\hline Autism spectrum/attention deficit hyperactivity disorder & $4(2.4)$ \\
\hline School phobia & $3(1.8)$ \\
\hline Eating disorder & $2(1.2)$ \\
\hline Other & $10(6.1)$ \\
\hline No psychiatric conditions specified & $98(59.8)$ \\
\hline \multicolumn{2}{|l|}{ Family history in first-degree relatives } \\
\hline Anxiety disorder & $29(17.7)$ \\
\hline Depression & $27(16.5)$ \\
\hline Chronic fatigue/chronic fatigue syndrome & $22(13.4)$ \\
\hline Arthritis/connective tissue disorder & $13(7.9)$ \\
\hline Fibromyalgia & $13(7.9)$ \\
\hline Chronic pain & $10(6.1)$ \\
\hline Psychosocial stressors & $7(4.3)$ \\
\hline Diabetes and other endocrine disorders & $6(3.7)$ \\
\hline Hypothyroidism/Hashimoto's thyroiditis & $4(2.4)$ \\
\hline Joint hypermobility & $4(2.4)$ \\
\hline Autism spectrum/attention deficit hyperactivity disorder & $4(2.4)$ \\
\hline Inflammatory bowel disease/coeliac disease & $3(1.8)$ \\
\hline Migraine & $3(1.8)$ \\
\hline No relevant family history specified & $82(50.0)$ \\
\hline
\end{tabular}

that alternative and complementary medicine services were not often used by patients. Victorian patients were significantly more likely to be seen in a specialist CFS service compared with other states (Victoria: 53\%, other states/territories: 16\%, $\chi^{2}=20.67, \mathrm{p}<0.001$ ), while patients in other states and territories were significantly more likely to be seen in adolescent medicine (Victoria: 5\%, other states/territories: $36 \%, \chi^{2}=25.14$, $\mathrm{p}<0.001$ ), use physiotherapy (Victoria: $8 \%$, other states/territories: $43 \%, \chi^{2}=27.35, \mathrm{p}<0.001$ ), occupational therapy (Victoria: $6 \%$, other states/territories: $38 \%, \chi^{2}=27.36, \mathrm{p}<0.001$ ) or rheumatology (Victoria: $7 \%$, other states/territories: $32 \%, \chi^{2}=16.9$, $\mathrm{p}<0.001)$. There were no other significant state-based differences in services used by patients.

Sleep hygiene was a treatment strategy recommended to almost all patients (95\%), with graded exercise therapy, a modified school programme/home tutoring, pacing/balancing activities or symptom management with medication/supplementation frequently recommended. There were no significant differences in treatment strategies used for Victorian patients compared with those in other states, with the exception of cognitive behavioural therapy, which was reported to be less likely to be recommended in Victoria than in other states (Victoria: 19\%, other states: $\left.71 \%, \chi^{2}=44.50, \mathrm{p}<0.001\right)$.

\section{DISCUSSION}

This study is the first to provide estimates of paediatrician-reported incidence of CFS in the Australian paediatric population, and the second worldwide to collect prospective incidence data. ${ }^{8}$ The estimated incidence in children aged 4-9 years was 0.25 per 100000 per annum (95\% CI 0.08 to 0.59$)$, while the estimated incidence in adolescents aged $10-17$ years was 6.38 per 100000 per annum (95\% CI 5.43 to 7.45$)$. The reported incidence for the state of Victoria (17.48 per 100000$)$ was substantially higher compared with other Australian states and territories (1.31-5.51 per 100 000).

There has been very little data available to quantify the clinical impression that CFS is rarely diagnosed in children aged under 10 years. Our results support this by demonstrating that CFS is uncommonly diagnosed in Australian children aged under 10 years. The only other study to document the incidence of CFS in younger children also reported this age range to have the lowest incidence. $^{20}$

Australian estimates of incidence of CFS in the current study is lower than estimates from other countries in the current literature. The estimated Victorian incidence is similar to that in other countries, ${ }^{820}$ suggesting incidence rates in Victoria could be more reflective of the true incidence of CFS. The underlying reasons for the geographic variation of diagnostic rates in Australia are unclear, but likely multiple. While the contribution of true geographical or biological factors in the observed incidence rates between regions cannot be ruled out based on the results of the current study, we believe that the differences between Victoria and the other states is most likely attributable to local phenomena affecting case ascertainment. The geographical reporting pattern of CFS in this study is not consistent with the overall pattern of APSU reporting rates across states, suggesting that results cannot be explained by the current study methodology. Contextual factors causing variation in diagnosis could relate to differences in access to specialists and/or diagnostic practices/culture (eg, lack of recognition or misconceptions about CFS). Further research is required to understand the influence of service provision on the epidemiology of this condition. For example, from the current study we cannot determine whether the incidence is greater in Victoria due to increased access to CFS specialist services or whether there is greater access to services due to increased need. Furthermore, it is unclear whether Victorian paediatricians are more likely to make a diagnosis of CFS as there is a dedicated service to refer to where access requires a formal diagnosis of CFS or whether greater access to specialist services in certain areas influences physician awareness and education of CFS, resulting in increased diagnostic rates.

Our results regarding gender ratio, ethnicity and symptom frequency are comparable to that in the international literature. ${ }^{815} 24-30$ Every study that reports ethnicity data, including our own, occurred in high-income countries with Caucasian majority populations. It is possible that the high proportion of Caucasian cases of CFS found in the literature reflects this ethnic group's majority in the population, rather than an increased susceptibility compared with other ethnicities.

Consistent with current results, patients most commonly have gradual onset of symptoms, onset linked to infectious illness and moderate to high severity. ${ }^{2892930}$ As in this study, existing 
literature has demonstrated associations between CFS and POTS, joint hypermobility, fibromyalgia, anxiety and depression. ${ }^{31-35}$ Although the rates of a family history of depression, anxiety and CFS in the current study need to be interpreted cautiously as they are based on self-report from the family or young person to the paediatrician, other research has suggested a likely association with depression, anxiety and CFS in first-degree relatives. ${ }^{3637}$

The protracted time between symptom onset and diagnosis observed in our study has also been observed in two Australian studies. ${ }^{3038}$ This delay is substantial, with $54 \%$ of patients not receiving a diagnosis, and therefore likely not having access to appropriate treatment, for over a year. Investigations recommended by the Australian clinical practice guidelines ${ }^{23}$ yielded very few abnormal results. This is consistent with the current practice of using diagnostic tests to rule out other medical conditions prior to diagnosis of CFS. Tests that most commonly yielded abnormal results, such as EBV serology and the ANA test, are not recommended by the guidelines, yet were requested for many patients. It is possible that because the existing CFS guidelines are based largely on adult care, these tests were not included as they are more relevant to a paediatric population.

Overall, the demographic and clinical characteristics, and approaches to diagnosis and management, do not vary greatly between Victoria and other states. Victorian patients were more likely to be referred to a specialist CFS service, while patients elsewhere were more likely to be seen in adolescent medicine and referred to individual allied health professionals and rheumatology. This difference likely reflects regional differences in service models and approaches to CFS management.

\section{Strengths and limitations}

This study used for case ascertainment, an established national surveillance system, which is independent of the research team. This reduces the potential for observer bias. All diagnoses were made by medical practitioners following a consultation and physical examination, which is likely to improve the validity of each diagnosis.

Although this is the most complete national dataset currently available for paediatric CFS in Australia, the study relies on self-reporting by paediatricians and some paediatricians may not report cases to the APSU. Paediatricians who are not confident in diagnosing CFS, do not believe in the existence of CFS, or the importance a diagnosis and providing management, may not report cases even though the child or adolescent meets the criteria. Accordingly, our results may underestimate the true incidence of paediatric CFS in Australia. It was not possible to include general practitioners in the data collection which may also result in an underestimate of incidence. It is possible that milder cases of CFS are not referred to paediatricians, and so were not identified in our study. The low proportion of severe and very severe cases may be influenced by selection bias, as these young people may be too sick to attend a consultation for diagnosis and so not captured by our study.

The age ranges used in the current study were informed by previous epidemiological research in paediatric CFS and were confined by the surveillance methodology used. Future research studies should consider using narrower age bands to further understand the incidence of CFS throughout childhood, particularly during the adolescent period.

\section{CONCLUSION}

This study suggests that there is substantial variation in diagnostic rates of CFS between Victoria and other states, by Australian paediatricians. The variation in diagnostic rates of CFS by paediatricians, plus protracted time to diagnosis, highlights the need for a national, coordinated approach to improving healthcare for children and adolescents with CFS. This should include prospective evaluation of health outcomes for adolescents with CFS and supporting an evidence-informed approach to management. Review and update of the national clinical practice guideline for CFS, with a systematic implementation strategy, will be crucial to ensuring children and adolescents with CFS receive access to more consistent care at national level.

\section{Author affiliations}

${ }^{1}$ Neurodisability and Rehabilitation, Murdoch Children's Research Institute,

Melbourne, Australia

${ }^{2}$ Victorian Paediatric Rehabilitation Service, Royal Children's Hospital Melbourne,

Melbourne, Victoria, Australia

${ }^{3}$ Paediatrics, The University of Melbourne, Parkville, Victoria, Australia

${ }^{4}$ Royal Children's Hospital Melbourne, Parkville, Victoria, Australia

${ }^{5}$ General Medicine, Royal Children's Hospital Melbourne, Parkville, Victoria, Australia

${ }^{6}$ Victorian Paediatric Rehabilitation, Monash Children's Hospital, Clayton, Victoria, Australia

${ }^{7}$ Sydney Children's Hospitals Network Randwick and Westmead, Westmead, New South Wales, Australia

${ }^{8}$ Adolescent Medicine, Princess Margaret Hospital, Perth, Western Australia, Australia ${ }^{9} \mathrm{SPACH}$, UWA, Perth, Western Australia, Australia

${ }^{10}$ Griffith University—Gold Coast Campus, Southport, Queensland, Australia

Acknowledgements The authors would like to thank Dr David Burgner, Murdoch Children's Research Institute, who provided advice in the interpretation of the study results. The authors would also like to thank the staff at the APSU Amy Phu and Marie Deverell for facilitation of reporting and management of the APSU database.

Contributors SK and AS conceptualised and designed the study, coordinated and supervised data collection and analysis, drafted the initial manuscript and reviewed and revised the manuscript. KR, CR, ST, KK, DNP, LL and SH designed the data collection instrument and reviewed and revised the manuscript. SE and $J R$ carried out the initial analyses, drafted the initial manuscript and reviewed and revised the manuscript. AH conceptualised and designed the study, and critically reviewed the manuscript for important intellectual content. All authors approved the final manuscript as submitted and agree to be accountable for all aspects of the work.

Funding This study was funded by the Mason Foundation and the Murdoch Children's Research Institute Government Infrastructure Grant.

Competing interests None declared.

Patient consent for publication Not required.

Ethics approval This study received ethics approval from The Sydney Children's Hospital Network Human Research Ethics Committee (LNR/14/SCHN/399).

Provenance and peer review Not commissioned; externally peer reviewed.

Data sharing statement Any unpublished data from this study are available on request by emailing the corresponding author.

\section{REFERENCES}

1 Fukuda K, Straus SE, Hickie I, et al. The chronic fatigue syndrome: a comprehensive approach to its definition and study. International Chronic Fatigue Syndrome Study Group. Ann Intern Med 1994;121:953-9.

2 Crawley E, Sterne JA. Association between school absence and physical function in paediatric chronic fatigue syndrome/myalgic encephalopathy. Arch Dis Child 2009:94:752-6.

3 Rowe PC, Underhill RA, Friedman KJ, et al. Myalgic Encephalomyelitis/Chronic Fatigue Syndrome Diagnosis and Management in Young People: A Primer. Front Pediatr 2017:5:121.

4 Werker CL, Nijhof SL, van de Putte EM. Clinical Practice: Chronic fatigue syndrome. Eur J Pediatr 2013;172:1293-8.

5 Nacul L, Kingdon CC, Bowman EW, et al. Differing case definitions point to the need for an accurate diagnosis of myalgic encephalomyelitis/chronic fatigue syndrome. Fatigue 2017;5:1-4.

6 Johnston S, Brenu EW, Staines D, et al. The prevalence of chronic fatigue syndrome/ myalgic encephalomyelitis: a meta-analysis. Clin Epidemiol 2013;5:105-10. 
7 Donegan K, Beau-Lejdstrom R, King B, et al. Bivalent human papillomavirus vaccine and the risk of fatigue syndromes in girls in the UK. Vaccine 2013;31:4961-7.

8 Nijhof SL, Maijer K, Bleijenberg G, et al. Adolescent chronic fatigue syndrome: prevalence, incidence, and morbidity. Pediatrics 2011;127:e1169-e1175.

9 Jones JF, Nisenbaum R, Solomon L, et al. Chronic fatigue syndrome and other fatiguing illnesses in adolescents: a population-based study. J Adolesc Health 2004;35:34-40.

10 Chalder T, Goodman R, Wessely S, et al. Epidemiology of chronic fatigue syndrome and self reported myalgic encephalomyelitis in 5-15 year olds: cross sectional study. BMJ 2003:327:654-5.

11 Minowa M, Jiamo M. Descriptive epidemiology of chronic fatigue syndrome based on a nationwide survey in Japan. J Epidemio/ 1996;6:75-80.

12 Lloyd AR, Hickie I, Boughton CR, et al. Prevalence of chronic fatigue syndrome in an Australian population. Med J Aust 1990;153:522-8.

13 Dobbins JG, Randall B, Reyes $M$, et al. The prevalence of chronic fatiguing illnesses among adolescents in the United States. Journal of Chronic Fatigue Syndrome 1997:3:15-27.

14 Jordan KM, Huang C-F, Jason LA, et al. Prevalence of pediatric chronic fatigue syndrome in a community-based sample. Journal of Chronic Fatigue Syndrome 2006;13(2-3):75-8.

15 Farmer A, Fowler T, Scourfield J, et al. Prevalence of chronic disabling fatigue in children and adolescents. Br J Psychiatry 2004;184:477-81.

16 Crawley EM, Emond AM, Sterne JA. Unidentified Chronic Fatigue Syndrome/myalgic encephalomyelitis (CFS/ME) is a major cause of school absence: surveillance outcomes from school-based clinics. BMJ Open 2011;1:e000252.

17 Dowsett EG, Colby J. Long-term sickness absence due to ME/CFS in UK schools: An epidemiological study with medical and educational implications. Journal of Chronic Fatigue Syndrome 1997:3:29-42.

18 Jordan KM, Ayers PM, Jahn SC, et al. Prevalence of fatigue and chronic fatigue syndrome-like illness in children and adolescents. Journal of Chronic Fatigue Syndrome 2000;6:3-21.

19 Rimes KA, Goodman R, Hotopf M, et al. Incidence, prognosis, and risk factors for fatigue and chronic fatigue syndrome in adolescents: a prospective community study. Pediatrics 2007; 119:e603-e609.

20 Bakken IJ, Tveito K, Gunnes N, et al. Two age peaks in the incidence of chronic fatique syndrome/myalgic encephalomyelitis: a population-based registry study from Norway 2008-2012. BMC Med 2014:12:167.

21 The Australian Paediatric Surveillance Unit. 2018: http://www.apsu.org.au/ (Accessed 3 Jul 2018).

22 AGDoH. Paediatrics \& child health: 2016 Factsheet. 2017. 2018 http://hwd.health. gov.au/webapi/customer/documents/factsheets/2016/Paediatrics $\% 20 \& \% 20$ child\% 20health\%20data.pdf (Accessed 28 Aug 2018).
23 Toulkidis V, Loblay R, Stewart G, et al. Chronic fatigue syndrome. Clinical practice guidelines-2002. Med J Aust 2002;176 Suppl:S17-S55.

24 Saidi G, Haines $L$. The management of children with chronic fatigue syndrome-like illness in primary care: a cross-sectional study. Br J Gen Pract 2006;56:43-7.

25 Bell DS. Illness onset characteristics in children with chronic fatigue syndrome and idiopathic chronic fatigue. Journal of Chronic Fatigue Syndrome 1997;3:43-51.

26 Rangel L, Garralda ME, Levin M, et al. The course of severe chronic fatigue syndrome in childhood. J R Soc Med 2000;93:129-34.

27 Vereker MI. Chronic fatigue syndrome: a joint paediatric-psychiatric approach. Arch Dis Child 1992;67:550-5.

28 Rowe KS, Rowe KJ. Symptom patterns of children and adolescents with chronic fatigue syndrome. International perspectives on child and adolescent mental health 2002:2:395-421.

29 Garralda ME, Rangel L. Impairment and coping in children and adolescents with chronic fatigue syndrome: a comparative study with other paediatric disorders. J Child Psychol Psychiatry 2004;45:543-52.

30 Knight S, Harvey A, Lubitz L, et al. Paediatric chronic fatigue syndrome: complex presentations and protracted time to diagnosis. J Paediatr Child Health 2013:49:919-24.

31 Barron DF, Cohen BA, Geraghty MT, et al. Joint hypermobility is more common in children with chronic fatigue syndrome than in healthy controls. J Pediatr 2002:141:421-5.

32 Stewart JM, Gewitz MH, Weldon A, et al. Patterns of orthostatic intolerance: the orthostatic tachycardia syndrome and adolescent chronic fatigue. J Pediatr 1999;135:218-25

33 Bell DS, Bell KM, Cheney PR. Primary juvenile fibromyalgia syndrome and chronic fatigue syndrome in adolescents. Clin Infect Dis 1994;18 Suppl 1(Suppl 1):S21-S23.

34 Bould H, Collin SM, Lewis $\mathrm{G}$, et al. Depression in paediatric chronic fatigue syndrome. Arch Dis Child 2013;98:425-8.

35 Crawley E, Hunt L, Stallard P. Anxiety in children with CFS/ME. Eur Child AdolesC Psychiatry 2009;18:683-9.

36 Collin SM, Tilling K, Joinson C, et al. Maternal and childhood psychological factors predict chronic disabling fatigue at age 13 years. J Adolesc Health 2015:56:181-7.

37 Rangel L, Garralda ME, Jeffs J, et al. Family health and characteristics in chronic fatigue syndrome, juvenile rheumatoid arthritis, and emotional disorders of childhood. J Am Acad Child Adolesc Psychiatry 2005;44:150-8.

38 Knight $S$, Harvey A, Towns $S$, et al. How is paediatric chronic fatigue syndrome/ myalgic encephalomyelitis diagnosed and managed by paediatricians? An Australian Paediatric Research Network Study. J Paediatr Child Health 2014:50:n/a-1007.

39 Toulkidis V, Loblay R, Stewart G, et al. Chronic fatigue syndrome: clinical practice guidelines 2002. Produced by a working group convened under the auspices of the Royal Australasian College of Physicians. Med J Aust 2002;176. 